\title{
Screening for thalassaemia among group of students of a higher institution - our experience
}

\author{
Norlelawati AT⿳a Siti Hadijah $M^{b}$, Siti Nor Haiza $H^{b}$, Rusmawati Ic , Salman MSc, \\ Abdul Wahab Ja, Naznin $M^{a}$

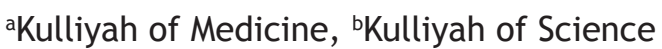 \\ International Islamic University Malaysia, Kuantan, Pahang, Malaysia \\ 'Department of Pathology, Hospital Tengku Ampuan Afzan, Kuantan, Pahang, Malaysia
}

\begin{abstract}
Introduction: Thalassaemia is an inherited blood disorder and is a significant public health alarm in Malaysia with many not knowing they are carriers of this haemoglobin disorders. Materials and methods: This study conducted a one off collection of blood samples from 72 Malays students of International Islamic University Malaysia (IIUM) in Kuantan. Blood samples were subjected to conventional haemoglobin analyses that include full blood count and picture, HPLC, Haemoglobin electrophoresis and H-inclusion test. All samples were also genotyped for alpha thalassaemia-1 of Southeast Asia ( $\alpha$-Thal1SEA). Result: There were 17(23.6\%) students who were diagnosed as thalassaemia carriers. Out of this, four (5.5\%) and six (8.3\%) students were presumptive B-thalassaemia trait and Haemoglobin-E trait as determined by the HPLC assay respectively. Nine (12.5\%) students were genotyped $\alpha$-Thal1SEA among whom two were also B-thalassaemia carriers. All thalassaemia cases had $\mathrm{MCH}$ of $<27 \mathrm{pg}$. Nonetheless, two out of six Haemoglobin-E trait and three out of nine $\alpha$-Thal1SEA carrier had MCV value of $>80 \mathrm{fL}$. Two out of four $(50 \%)$ presumptive $B$-thalassaemia trait and one out of six (17\%) students of presumptive Haemoglobin-E trait had family history of thalassaemia respectively. Conclusion: The high occurrence of the three common types of thalassaemia carrier $(B, \mathrm{Hb}-\mathrm{E}$ and $\alpha-T h a l 1 \mathrm{SEA}$ thalassaemia) in our small group of subjects could be due to better participation of students who had family history of thalassaemia. The study reaffirmed the importance of molecular study for detection of alph $\alpha$-thalassaemia and the use of $\mathrm{MCH}$ value of $<27 \mathrm{pg}$ rather than MCV value of $<80 \mathrm{fL}$ for prediction of thalassaemia.
\end{abstract}

KEYWORDS: Thalassaemia, screening, diagnosis, genetic carriers.

\section{INTRODUCTION}

Thalassaemia is a group of inherited autosomal recessive blood disorders characterized by impaired or the absence of production of normal $a$ or $B$ globin chain peptide. These groups of single gene disorders have an estimated $5 \%$ prevalence as carriers. ${ }^{1}$ In $\mathrm{Ma}$ laysia the prevalence is estimated to range between $3 \%$ and $50 \%$ for Haemoglobin-E (Hb-E), 3\% and 16\% for a- thalassaemia and slightly lower for B-thalassaemia and Constant Spring carriers of 3\% and $4 \%$ and $1 \%$ and $4 \%$ respectively. ${ }^{2}$ The estimated prevalence for $\mathrm{Hb}-\mathrm{E}$ and alpha thalassaemia in Malaysia is similar to the reported prevalence in Thailand, a neighboring country. ${ }^{3}$

Symptomatic thalassaemia major and intermedia requires life long-term medical care and support. ${ }^{4}$ Population screening for carrier detection has been advo-

\section{Corresponding author;}

Dr Norlelawati A. Talib

Department of Basic Medical Sciences

Faculty of Medicine

International Islamic University Malaysia

Kuantan, Pahang.

Email: noleata@yahoo.com cated to reduce it occurrence and is being practiced in many countries. ${ }^{5,6}$ The best mechanism to do this, however, is still debatable since this would require huge financial resources to cover various areas such as the counseling service and genetic support. In Malaysia, most community health centers are equipped with blood cell analyzer, and it is therefore feasible to adopt the screening method based on the MCV of $<80 \mathrm{fL}$ or $\mathrm{MCH}$ of $<27 \mathrm{pg}$.

In this study, a complete work-up for thalassaemia which include conventional methods for haemoglobin analyses and molecular study for $\alpha$-Thal1SEA deletion were performed in our group of students who responded to our advertisement for thalassaemia screening. To mimic on site population screening, a one off blood collection was done.

\section{MATERIALS AND METHODS}

Subjects and blood analyses

The entire study was carried out over a period of three months following approval from the ethics and research committees of International Islamic University of Malaysia (IIUM). Study subjects were medical and science students of the IIUM, who were recruited by announcement on notice boards. To mimic a population-screening programme, blood sample from all 72 Malay students aged 20-25 years was collected on the same day.

The handling and storage of blood samples were in accordance with standard laboratory practice. HPLC 
assay on D-10 HPLC Haemoglobin Testing System (BioRad, USA) was performed within two days of the collection of the blood samples. The full blood count was performed within 24 hours after the blood collection. Other standard tests performed were the haemoglobin electrophoresis and $\mathrm{H}$ inclusion test. The full blood count was performed on automated ADVIA $® 120$-Haematology System. The haemoglobin electrophoresis was run on Hydrasys (Serbia, USA). $\mathrm{H}$-inclusion test was performed by a junior laboratory technologist.

The chromatographic profiles and the $\mathrm{HbA} 2$ and $\mathrm{Hb} \mathrm{F}$ levels determined by HPLC assays were interpreted based on the study by Fucharoen et al. ${ }^{7}$ Thus, a presumptive $B$-thalassaemia trait was made when $\mathrm{HbA} 2$ level was from 4.2 to $6.8 \%$ while presumptive $\mathrm{Hb}-\mathrm{E}$ trait and $\mathrm{Hb}-\mathrm{E}$ homozygous were made when the $\mathrm{HbA} 2$ was from $25 \%$ to $36 \%$ and $85 \%$ to $95 \%$ respectively. All samples were subjected to $\alpha$-Thal1SEA molecular study regardless of the HPLC finding. Results were analysed using the Statistical Package for Social Sciences version 11 (SPSS Inc., Chicago, Illinois, USA). A $p$ value of $<0.05$ was considered as statistically significant.

Molecular analysis of $\alpha$-Thal1SEA thalassaemia.

DNA was extracted by standard method using column separation method (QiaAmp Blood Mini Kit, Qiagen). The three primers for $\alpha$-Thal1SEA genotyping were as described by Chang et al. ${ }^{8}$ The Gap Polymerase Chain Reaction assay consisted of $200 \mu \mathrm{m}$ of each dNTP, 2.5 $\mathrm{mM} \mathrm{MgCl2}, 1 \mathrm{X}$ Q solution (Qiagen, Hilda, Germany), 2.5 U HotStar Taq DNA polymerase, 100-200 ng of genomic DNA and distilled water made to $50 \mu \mathrm{L}$ of cycle reaction. Reactions were run in thermal cycler $(9700$ Gene Amp, Applied Biosystem, USA). An initial 10 minutes denaturation at $96^{\circ} \mathrm{C}$ was followed by 35 cycles of $96^{\circ} \mathrm{C}$ denaturation, $60^{\circ} \mathrm{C}$ annealing and $72^{\circ} \mathrm{C}$ extension, each for 30 seconds. A final extension at $72^{\circ} \mathrm{C}$ for 10 minutes ended up the reaction. All amplified products were run on $1.5 \%$ agarose gel electrophoresis and viewed on gel documentation system. The expected product for heterozygous $\alpha$-Thal1SEA deletion is 314 and $195 \mathrm{bp}$ whilst the homozygous $\alpha$-Thal1SEA deletion is 195bp. The expected product for $\alpha-T h a l 1 S E A$ negative amplicon is $314 \mathrm{bp}$. The DNA of a known $\alpha-$ Thal1SEA thalassaemia patient was used as the positive control. Positive samples were repeated at least once.

\section{RESULTS}

Of the 72 Malay students who responded for thalassaemia screening, the majority was females $(87.5 \%)$. The haemoglobin $(\mathrm{Hb})$ levels of all the students were normally distributed with the mean $\mathrm{Hb}$ of $13.9 \mathrm{~g} / \mathrm{dL}$ in males; and $12.3 \mathrm{~g} / \mathrm{dL}$ in females. Ten students (13.9\%) had low $\mathrm{Hb}$ level of whom only one was a male student (cut off $\mathrm{Hb}<11.5 \mathrm{~g} / \mathrm{dL}$ for female and $<12.5 \mathrm{~g}$ / $\mathrm{dL}$ for male).

There were four (5.5\%) students with a presumptive B-thalassaemia trait and six (8.3\%) with $\mathrm{Hb}-\mathrm{E}$
Table 1: Data on MCV values and types of thalassaemia

\begin{tabular}{|c|c|c|c|}
\hline & $\begin{array}{c}M C V \geq 80 \\
f L \\
(n=53)\end{array}$ & $\begin{array}{c}M C V< \\
80 \mathrm{fL} \\
(n=19)\end{array}$ & p value \\
\hline B-thalassaemia trait & $\mathbf{0}$ & 4 & \\
\hline $\begin{array}{l}\text { Non B-thalassaemia } \\
\text { trait }\end{array}$ & 53 & 15 & 0.004 \\
\hline Hb-E trait & 2 & 4 & \\
\hline Non Hb-E trait & 51 & 15 & 0.038 \\
\hline -sea/aa & 3 & 6 & \\
\hline Non --sea/aa & 50 & 13 & 0.008 \\
\hline
\end{tabular}

*Fisher-exact test

$\begin{array}{llllllll}1 & 2 & 3 & 4 & 5 & 6 & 7\end{array}$

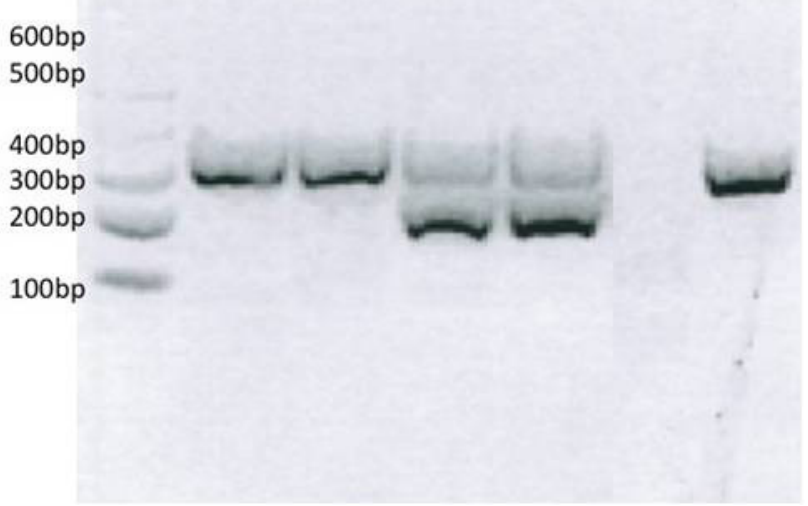

Figure 1: Gap PCR for --sea/aa thalassaemia. Lane 1; 100bp marker, Lane 2,3 : Negative (315bp), Lane 4,5, Positive (194 \& 315bp), Lane 6: Blank and Lane 7: Control negative (315bp)

trait. Two out of four students with the presumptive B-thalassaemia trait was a twin who had strong family history of clinical thalassaemia. The molecular analysis detected nine (12.5\%) students with $\alpha$-Thal1SEA genotype (Figure 1), two of whom were also $B$-thalassaemia carriers detected earlier through HPLC assay. None had a positive $\mathrm{H}$ inclusion test. In total of 17 (23.6\%) students were diagnosed as thalassaemia carriers (presumptive or through molecular study). 
Out of 72 samples studied, 19 (26.38\%) subjects had both low MCV and MCH value. All subjects diagnosed as thalassaemia carrier had $\mathrm{MCH}$ of $<27 \mathrm{pg}$ thus further statistical analyses on this parameter were deemed unnecessary. All the presumptive B-thalassaemia trait subjects had MCV levels of $<75 \mathrm{fL}$. There was a significant association between the MCV level of $<80 \mathrm{fL}$ with $\alpha$-Thal1SEA thalassaemia (two tails Fisher's Exact test, $p=0.008$ ) and MCV level of $<80 \mathrm{fL}$ with Haemoglobin- $E$ trait (Fisher exact test, $\mathrm{p}=0.038$ ) (Table 1). Nevertheless, the MCV value was normal ( $>80 \mathrm{fL}$ ) in two out of six subjects with presumptive diagnosis of $\mathrm{Hb}-\mathrm{E}$ trait and three out of nine subjects with $\alpha$-Thal1SEA. The median of $\mathrm{Hb}$ irrespective of sex for B-thalassaemia carriers was $9.8 \mathrm{~g} / \mathrm{dL}$, while the mean for $\mathrm{Hb}-\mathrm{E}$ traits and $\alpha$-Thal1SEA carriers were $13.3 \mathrm{~g} / \mathrm{dL}$ and $11.5 \mathrm{~g} /$ $\mathrm{dL}$ respectively. The median $\mathrm{Hb}$ for subjects with concomitant evidence of $B$-thalassaemia and $\alpha$-Thal1SEA was normal at $12.5 \mathrm{~g} / \mathrm{dL}$. There were two subjects with hypochromic microcytic anemia but with normal haemoglobin analysis findings. No further investigation was done to determine another possible cause/s of anemia.

Counseling was done for students with presumptive $\mathrm{B}$-thalassaemia carriers and $\mathrm{Hb}$-E carriers but none of a-thalassaemia carrier since the result was only available after the students left the university. Two out of four students of presumptive B-thalassaemia carriers and one out of six students of $\mathrm{Hb}$-E carriers had family members with thalassaemia. Family history of thalassaemia could not be determined in all the cases of SEA thalassaemia carriers except in one who was also positive for B-thalassaemia carriers and had family history of thalassaemia.

\section{DISCUSSION}

The standard protocol for screening of thalassaemia normally follows a defined flowchart wherein the erythrocyte indices are taken as the preliminary test. Generally only those with MCV level of $<80 \mathrm{fL}$ and/or $\mathrm{MCH}$ level of $<27 \mathrm{pg}$ are further tested using HPLC and molecular analyses. In Malaysia, $\mathrm{MCH}$ level of $<27 \mathrm{pg}$ is adopted as the cut-off value. The MCV level was of special interest in our study subjects since blood samples were collected and analysed within 24 hours of collection and has been the preferred indices in other screening centres. ${ }^{9}$

Even though the MCV value of < $80 \mathrm{fL}$ was used for definition of microcytic red blood cells, all the presumptive B-thalassaemia trait subjects in our study had MCV level of $<75 \mathrm{fL}$, which was similar to previous observations. ${ }^{10}$ Mah et al11 however, found that using a cut of value of $<75 \mathrm{fL}$ had led to missing detection of almost $3 \%$ of $B$-thalassaemia carriers and $4 \%$ of $\alpha-$ Thal1SEA carrier subjects in the Chinese population, while the use of standard cut-off value of $80 \mathrm{fL}$ could detect both carrier states. The second observation was not replicated in our study as three out of nine (33.3\%) of $\alpha$-Thal1SEA genotyped subjects had MCV of $>80 \mathrm{fL}$. Our data agrees with the findings of previous studies that concluded a proportion of $\mathrm{Hb}-\mathrm{E}$ and a-thalassaemia carrier individuals would be missed if the MCV $<80$ fL cut-off value was used. ${ }^{11,12}$ Using the $\mathrm{MCH}$ value is most probably the preferred choice because in practice it might be difficult to analyze MCV values within six hours of collection. This is especially true if the collection centres are at the remote areas. In our study, we found all the thalassaemia carrier subjects had $\mathrm{MCH}$ value of less than $<27 \mathrm{pg}$. This approach, however, is not without deficiency as some $\mathrm{Hb}-\mathrm{E}$ trait and a-thalassaemia subjects in a larger study were shown to have higher $\mathrm{MCH}$ value. ${ }^{13}$ All of our HbE trait subjects $(n=6)$ had low $\mathrm{MCH}$ whilst two subjects had $M C V>80 f L$. Thus, $M C H$ rather than MCV was the preferred parameter for screening of thalassaemia. Using the preset cut-off MCV value alone is confounded with missed detection of $\mathrm{Hb}-\mathrm{E}$ trait.

The use of $\mathrm{H}$-inclusion test for screening of a-thalassaemia is an observer dependent, laborious and has a poor sensitivity. Even though the staining procedures were carried out by following the standard $\mathrm{H}$-inclusion protocol, fresh sample of control positive blood was not available on the day of this examination. This could contribute to the failure in identifying any positive $\mathrm{H}$-inclusion in all subjects with $\alpha$-Thal1SEA genotype. We believe the observer lacked of experience in interpreting $\mathrm{H}$-inclusion test had also contributed to this failure.

The finding of this study does not reflect the prevalence of thalassaemia among Malays in Malaysia since the sample size was very small. However, it was observed that the distribution of $\mathrm{Hb}$-E carriers among our Malay students were within the range of the previous review on thalassaemia in the general population, and not very different either to a recent study done in Thailand. ${ }^{14}$ There were over representation of $\alpha$-Thal1SEA and $B$-thalassaemia carrier subjects as compared to previous studies..$^{15,16}$ It should be noted, however, that data from our study was very similar to the prevalence observed amongst Malays in Singapore, ${ }^{17}$ a southern neighbouring country that has similar multiracial communities. The percentage of $\mathrm{Hb}-\mathrm{E}$ and $B$-thalassaemia carriers were also quite similar to the data done on blood donors. ${ }^{18}$ The study, however, did not examine for $\alpha$-Thal1SEA genotype. As this purpose of study was not to determine the prevalence of thalassaemia in general community, the high occurrence of thalassaemia in our subjects could be due to significant participation from students who had a family history of thalassaemia. The over-representation of subjects with $\alpha$-Thal1SEA genotype could also be due to the contribution from subjects of mixed ethnic groups but were identified as Malay in this study.

\section{CONCLUSION}

This study reaffirms the importance of molecular study for detection of alph $\alpha$-thalassaemia carrier. The $\mathrm{MCH}$ value of $<27 \mathrm{pg}$ is the preferred parameter for prediction of thalassaemia carrier as the use of MCV of < $80 \mathrm{fL}$ has led to miss detection of some Haemoglobin- $\mathrm{E}$ and $\alpha$-Thal1SEA carrier. Thalassaemia is prevalent in Malays; this study supports the opinion that popula- 
tion screening for common types of thalassaemia is recommended.

\section{ACKNOWLEDGEMENTS}

We would like to thank the staffs of Molecular Research Laboratory and Biochemistry \& Haematology Laboratory, Department of Basic Medical Sciences, Kulliyyah of Medicine and all the study participants. This work was supported by a grant from International Islamic University Malaysia.

\section{REFERENCES}

1. World Health Organization. Thalassaemia and other haemoglobinopathies. Report by the Secretariat: Executive Board 118th Ses sion, May 2006.

2. George E. Thalassaemia carrier diagnosis in Malaysia. ThalIDS 1998: 1-16.

3. Fucharoen S, Winichagoon P. Haemoglobinop athies in Southeast Asia. Haemoglobin 1987; 11:65-88.

4. Ismail A, Campbell MJ, Mohd Ibrahim H, Jones GL. Health related quality of life in Malaysian children with thalassaemia. Health Qual Life Outcomes 2006; 4:39.

5. Bozkurt G. Result from the North Cyprus Thalassaemia Prevention Program. Haemo globin 2007; 31:257-64.

6. Samavat A, Modell B. Iranian national thalas saemia screening programme. BMJ 2004; 329:1134-7.

7. Fucharoen S, Winichagoon P, Wisedpanichkij $\mathrm{R}$, et al. Prenatal and postnatal diagnoses of thalassaemias and haemoglobinopathies by HPLC. Clin Chem 1998; 44:740-8.

8. Chang JG, Lee LS, Lin CP, Chen PH. Rapid Diagnosis of $\alpha$-Thalassaemi $\alpha-1$ of Southeast Asia Type and hydrops fetalis by polymerase chain reaction. Blood 1991; 78:853-4.

9. Tang M, Tse KT, Ghosh A, et al. Guidelines of Antenatal Thalassaemia Screening. Pub lished by The Hong Kong College of Obstetri cian and Gynaecologist. Oct 2003.

10. George E, Jamal AR, Khalid F, Osman KA. High performance liquid chromatography (HPLC) as a screening tool for classical bet $\alpha-$ thalassaemia trait in Malaysia. Malaysian J Med Sci 2001; 8:40-46.

11. Ma ESK, Chan AYY, Ha SY, et al. Thalassaemia screening based on red cell indices in the Chinese. Haematologica 2001; 86:301-11.

12. Sanchaisuriya K, Fucharoen S, Fucharoen G, et al. A reliable screening protocol for thala ssaemia and haemoglobinopathies in preg nancy: an alternative approach to elec tronic blood cell counting. Am J Clin Pathol 2005; 123:113-8.
13. Fucharoen G, Sanchaisuriya K, Sae-ung N, et al. A simplified screening strategy for thalassaemia and haemoglobin $\mathrm{E}$ in rural communities in South-East Asia. Bull World Health Organ 2004; 82:364-72.

14. Choopayak C, Mirasena S, Poodendaen C, et al. Thalassaemia mutation in lower north ern Part of Thailand. Naresuan University Journal 2005; 13:19-29.

15. George E, Khuzaiah R. Malays with thalas saemia in West Malaysia. J Trop Med 1984; 36:123-25.

16. George E, Li HJ, Fei YJ, et al. Types of thala ssaemia among patients attending a large university clinic in Kuala Lumpur, Malaysia. Haemoglobin 1992; 16:51-66.

17. Kham SK, Quah TC, Loong AM, et.al. A molecular epidemiology study of thalassae mia using newborn's cord blood in multiracial Asian population in Singapore: results and recommendations for a population-screening program. J Pediatr Hematol Oncol 2004; 26: 817-9.

18. Rosline H, Ahmed SA, Al-Joudi FS, et al. Thalassaemia among blood donors at the hospital Universiti Sains Malaysia. Southeast Asian J Trop Med Public Health 2006; 37:54952. 